\title{
A tuberculose através do século: ícones canônicos e signos do combate à enfermidade
}

Tuberculosis through the century: canonic icons and signs of the fight against the disease

José Leopoldo Ferreira Antunes 1

Eliseu Alves Waldman 2

Mirtes de Moraes 3

\footnotetext{
1 Departamento de Odontologia Social, Faculdade de Odontologia da Universidade de São Paulo, av. prof. Lineu Prestes 2.227, 05508-900 São Paulo, SP. leopoldo@fo.usp.br

2 Faculdade de Saúde Pública da Universidade de São Paulo

3 Pontifícia Universidade Católica de São Paulo
}

\begin{abstract}
Tuberculosis has marked a strong presence in Brazil, throughout the twentieth century. The present study reviews canonic icons, signs and meanings related to tuberculosis, as a resource to approach social representations of the disease. Dispensaries have been organized to provide health services, education and social attendance to patients. Sanatoriums have been built, devoted to the isolation and long term treatments. The diffusion of spittoons and the habit of spitting, unusual for today, pointed out the belief of their usefulness in preventing the contagion. Screening chest radiography spread out the search for new cases of the disease. These were some of the elements gathered with the aim of supplying information to the study of tuberculosis experience, from the point of view of those who feared the contagion, who observed prophylactic measures, who suffered the disease's biological injuries, who had a daily relationship with their metaphors. As a conclusion, we delineate the epidemiological profile of a whole century of tuberculosis in Brazil, highlighting the perceived changes of the disease's insertion upon the social imaginary.

Key words Tuberculosis; Social Representation of the Disease; History and Health
\end{abstract}

Resumo A tuberculose marcou forte presença no Brasil, ao longo de todo o século XX. No presente estudo, são passados em revista ícones canônicos, signos e significados associados à moléstia, na qualidade de recursos de aproximação às representações sociais da doença. Os dispensários organizados para prover educação sanitária e assistência médica e social aos doentes; os sanatórios, dedicados ao isolamento nosocomial e tratamento prolongado; $o$ hábito de escarrar e as escarradeiras, insólitos para os padrões atuais, cuja difusão acreditouse auxiliar no combate à enfermidade; a abreugrafia, no rastreamento de novos casos. Esses são alguns dos elementos recuperados com o intuito de coligir informações em apoio à perspectiva de se recuperar a história da tuberculose do ponto de vista daqueles que temeram o contágio, que atentaram para os rigores de sua prevençãa, que sofreram os danos biológicos causados pela doença, que conviveram com suas metáforas. A título de conclusão, esboçase o perfil epidemiológico de um século de tuberculose no Brasil, apontando para as mutações reconhecidas na inserção da doença no imaginário social.

Palavras-chave Tuberculose; Representação Social da Doença; História e Saúde 


\section{A tuberculose através do século: ícones canônicos e signos do combate à enfermidade}

A história da tuberculose no Brasil consagrou ao longo do século XX vários ícones canônicos de intenso significado para os doentes e para os estabelecimentos, programas e profissionais que se dedicaram à profilaxia da moléstia. São objetos, procedimentos, instituições e outros elementos relacionados à doença, cuja marca se imprimiu de modo indelével na organização social. São conteúdos significativos que chegaram a impressionar o imaginário de uma sociedade que ainda hoje preserva a sua lembrança.

A escarradeira de cerâmica decorada, signo contundente do receio de contágio durante as primeiras décadas, esteve presente nas mais luxuosas residências e nos recintos públicos, como teatros e igrejas, enquanto cortiços e ambientes populares dispunham versões menos requintadas do artefato. A figura dramática do isolamento e morte nos sanatórios instalados em montanhas por vezes referidas como mágicas. A hemoptise, o jorro de sangue pelo nariz, prenúncio tardio da morte iminente. $\mathrm{O}$ número trinta e três, pronunciado com expectativa e ansiedade, ao frio contato do estetoscópio. O pneumotórax e a toracoplastia, as temidas intervenções cirúrgicas.

Embora tenha vivido no século passado, a personalidade emblemática da enfermeira Anna Nery constituiu importante referência para a Campanha Nacional contra a Tuberculose, nos anos 40 (Barreira, 1993). Doença crônica, envolvendo longos períodos de internação, a tuberculose propiciou a projeção social do valor da enfermagem no Brasil. A introdução da estreptomicina e do esquema tríplice de associação de medicamentos (estreptomicina, hidrazida e ácido paraminossalicílico) no tratamento da enfermidade; a vacina BCG; o empenho dos dispensários em obter, através da educação sanitária, a adesão dos pacientes aos tratamentos prolongados; a abreugrafia no rastreamento em massa dos indivíduos que já disseminavam a doença mesmo antes de serem identificados como doentes; a pesquisa da imunidade individual por meio do teste de Mantoux - aplicação subcutânea de PPD (derivado de protéico purificado do Mycobacterium tuberculosis), que podia expressar a infecção pelo bacilo da tuberculose quando, no local de aplicação, resultasse um nódulo, de- pendendo de sua dimensão. Esses, dentre outros, poderiam ser lembrados como marcos dos esforços de assistência e controle dirigidos à tuberculose, de meados do século em diante.

O período mais recente, a partir do início da década de 1980, parece não ter sido menos pródigo na produção de conteúdos significativos distintivos da enfermidade. O surgimento da AIDS promoveu rapidamente uma profunda modificação no panorama epidemiológico das doenças infecciosas em todo o globo e, em especial, sua associação com a tuberculose propiciou condições para o recrudescimento da mortalidade provocada pela moléstia. As condições favoráveis ao surgimento e disseminação de cepas de $M$. tuberculosis resistentes às drogas aplicadas em sua terapêutica passaram a dificultar o controle da doença. A consolidação de grandes centros urbanos, em todas as regiões do país, reforçou antigas preocupações ante a associação da enfermidade com a privação e a iniqüidade social, com os movimentos migratórios, com as precárias condições de habitação nas cidades e com a baixa efetividade dos programas de assistência e controle.

O presente estudo teve por finalidade revisitar a história da tuberculose no século XX, em busca dos significados que lhe foram atribuídos por aqueles que experimentaram, na doença, tanto as agruras de suas manifestações mórbidas como os rigores dos serviços que puderam ser efetivados em cada conjuntura. Esta foi a estratégia selecionada para tentar recuperar algumas das expressões que cem anos de doença e morte, de profilaxia e tratamento, repercutiram sobre uma população que mesclou resignação e inconformidade, em todo um século de resistência aos efeitos muitas vezes devastadores da tuberculose.

Nos últimos anos, o campo da história e saúde tem promovido diferentes tentativas de reconstituir a experiência da doença, segundo o ponto de vista daqueles que a vivenciaram. Embora não seja uma perspectiva de todo original e apesar de várias iniciativas nessa direção, poder-se-ia dizer que contar a história das doenças pela ótica dos doentes é tarefa ainda a ser realizada. Valorizada pela nouvelle histoire, essa diretriz de estudos apresenta dificuldades, as quais não deixam de configurar um incentivo à criatividade de estudiosos e pesquisadores.

Conquanto os serviços de saúde tenham sistematicamente produzido anotações passí- 
veis de apreensão para a pesquisa histórica, o discurso dos pacientes só pôde ser registrado de forma fragmentária e dispersa em acervos de diferentes ordens. Nesse sentido, o esforço analítico para a integração desses acervos deveria contemplar múltiplos enfoques, buscando-se a história dos significados que a tuberculose conheceu nos próprios tuberculosos, a experiência vívida da enfermidade, através das muitas entradas da doença na literatura, na imprensa e nas artes plásticas. Dever-se-ia também buscar uma interação interdisciplinar com a análise epidemiológica, a clínica médica, a antropologia cultural, o estudo das repercussões das políticas e programas de saúde, os depoimentos pessoais e as histórias de vida, como possibilidades a serem tentadas.

Pioneiros nessa perspectiva, René e Jean Dubos publicaram, originalmente em 1952, o livro A peste branca: tuberculose, homem e sociedade (Dubos \& Dubos, 1996). Em seu estudo, o casal ponderava que imprecisões de diagnóstico, convenções sociais e tabus interferiam nos registros oficiais da doença e tendiam a distorcer as asserções científicas, deixando esses registros quase sempre incompletos. Por essa razão, eles teriam preferido buscar outro tipo de conhecimento, menos preciso na aparência, porém mais confiável e revelador, aquele manifestado em cartas, diários e biografias; novelas, peças de teatro e trabalhos artísticos; no folclore e na história; através dos quais as pessoas testemunharam a ubíqua presença da tuberculose em suas vidas.

Seguindo a mesma diretriz, Sheila M. Rothman (1994) reuniu diversas narrativas de doen$c ̧ a$, em cartas, depoimentos de familiares e outros registros deixados por tuberculosos nos séculos XIX e XX, relatando-os em seu livro Vivendo na sombra da morte: tuberculose e experiência social da doença na história americana. Em Vidas febris: a tuberculose na cultura americana desde 1870, Katherine Ott (1996) enfatizou a cultura material associada à doença, abordando sua recente mudança de significados: do período em que se referiam as virtudes conferidas aos tuberculosos, a espiritualidade elevada, o sofrimento que enaltece, à concepção da doença como o inimigo microscópico que campeia nos redutos da pobreza.

O Brasil também tem inspirado pesquisas nessa direção. Já no final da década de 1940, em um trabalho pioneiro e de leitura instigante, Oracy Nogueira (1950) descreveu a experiência social dos doentes em Campos do Jordão, sublinhando suas manifestações psicológicas, o regime de funcionamento dos sanatórios e pensões, bem como o ambiente tuberculoso da cidade. Em um período mais recente, a Casa de Oswaldo Cruz, no Rio de Janeiro, constituiu um acervo de depoimentos de doentes e profissionais de saúde que estiveram envolvidos na luta contra a tuberculose (Porto \& Nascimento, 1995; Fernandes, 1993). E, para citar outro trabalho aplicado à recuperação da vivência pessoal da doença, Cláudio Bertolli Filho $(1992,1993)$ explorou as perspectivas documentais para a história social do tuberculoso, no contexto de um intenso esforço de pesquisa envolvendo os prontuários clínicos dos pacientes atendidos no Hospital Central da Santa Casa de Misericórdia, em São Paulo.

Com o intuito de se associar a esses esforços, o presente estudo procurou sintetizar uma visão panorâmica sobre signos e significados associados à doença, os quais tiveram ampla repercussão social ao longo de todo um século de lides com a tuberculose.

\section{A vida nos sanatórios, a doença nos dispensários}

As diretrizes internacionais firmadas no final do século XIX para o combate à tuberculose estiveram centradas em dois estabelecimentos: o dispensário e o sanatório. Enquanto o primeiro se dedicava à procura dos focos de contágio, à difusão de noções de higiene e à prestação de assistência médica e social aos doentes inscritos, o segundo esteva voltado ao isolamento nosocomial e tratamento continuado. Através desse binômio, pretendia-se dificultar a disseminação da enfermidade (Campos, 1965).

Até o início dos anos 20, a ação governamental em saúde estivera dirigida preferencialmente às doenças de caráter epidêmico, como a varíola, a peste e a febre amarela, cujo impacto sobre a população ameaçava as políticas de incentivo à migração e ao desenvolvimento agrário. $\mathrm{O}$ atendimento aos tuberculosos ficava concentrado nas Santas Casas, onde, no entanto, não havia áreas reservadas para o isolamento de doentes infectantes. As primeiras iniciativas voltadas à organização de serviços diferenciados de atenção aos tuberculosos foram movidas no campo da filantropia, em especial por intermédio da Liga Brasileira contra a Tuberculose, no Rio de Janeiro e, em São 
Paulo, da Associação Paulista de Sanatórios Populares para Tuberculosos, depois Liga Paulista contra a Tuberculose (São Paulo, 1957), associações criadas pelas elites médica e intelectual.

Dilene Raimundo do Nascimento (1991) relatou que a Liga Brasileira contra a Tuberculose fora instalada em 4 de agosto de 1900, com o arcebispo do Rio de Janeiro presidindo a sessão solene e a presença do presidente Campos Sales, alguns de seus ministros e várias figuras de prestígio nas esferas política, social e artística. Os objetivos da Liga consistiam na ampla divulgação de esclarecimentos sobre como evitar o contágio e sobre recursos terapêuticos, além da construção de dispensários e sanatórios. Ademais, a Liga propugnava maior participação do Estado nos esforços de prevenção e controle, através da reestruturação de serviços e cumprimento de preceitos já previstos pelas posturas municipais. Embora esses objetivos não tenham sido realizados por falta de recursos, a Liga chegou a manter alguns dispensários, com contribuições de seus sócios, subvenções oficiais, organização de festas, recursos de associações beneficentes, igrejas, fábricas e escolas. Este foi o caso do Dispensário Azevedo Lima, criado em 1902, e do Dispensário de São Cristóvão, em 1911, ambos no Rio de Janeiro. A partir de 1920, quando a criação da Inspetoria de Profilaxia da Tuberculose marcou o início de uma intervenção estatal mais intensiva no combate à doença, novos dispensários puderam ser organizados.

Nos debates médicos do período, reiterava-se a questão da inserção urbana desses estabelecimentos e a dificuldade de atender simultaneamente às demandas de sua proximidade e distância aos núcleos de povoação mais intensa. O Dispensário Central era bem servido pelas linhas de trens e bondes; em contrapartida, apresentava intenso ruído devido ao tráfego local. O Dispensário de Botafogo, ao contrário, apresentava-se silencioso, mas a distância ao centro dificultava-lhe o acesso. O Dispensário Ramos localizava-se em uma rua tranqüila, porém tinha o inconveniente de não dispor de espaço suficiente para atender a todos que o procuravam. E o Dispensário de Sampaio, também de fácil acesso, sofria com a poeira e o barulho causados pela proximidade à estrada de ferro (Nascimento, 1991).

Em geral, os dispensários abriam ao meiodia e fechavam às 16 horas, sendo a manhã reservada para a limpeza dos recintos, com a apli- cação de uma solução anti-séptica sobre o piso. O tratamento nos dispensários destinavase preferencialmente aos pobres e suas atividades abrangiam exames diagnósticos, encaminhamento para consultórios médicos e serviços de enfermagem. Era também usual a assistência social aos doentes necessitados, com o apoio de instituições filantrópicas, como a Cruzada Nacional contra a Tuberculose, fundada em 1921, e a Associação de Socorro aos Tuberculosos, criada em 1925, que distribuíam medicamentos, roupas e alimentos, como leite condensado e farinha. Também entrava na pauta de atribuições dos dispensários o fornecimento por empréstimo de camas e de cadeiras especiais para os pacientes tornados inválidos pela tuberculose. Os doentes que recebiam medicação gratuita eram encaminhados para o gabinete de educação, recebendo das enfermeiras conselhos profiláticos, lenços e escarradeiras.

Em 1922, foi criado no Rio de Janeiro o Serviço de Enfermeiras da Saúde Pública, voltado à difusão das atividades educativas em saúde iniciadas pelos dispensários. As enfermeiras visitadoras adentravam os lares, para instruir as famílias sobre os cuidados devidos à tuberculose e buscar a adesão dos doentes para o tratamento. Além disso, distribuíam panfletos e publicações, explicando como evitar a doença e como proceder para obter tratamento. No entanto, as muitas dificuldades no reconhecimento precoce da doença restringiam a eficácia desses esforços.

A partir de 1924, os dispensários passaram a aplicar uma técnica cirúrgica coadjuvante do tratamento antituberculose, o pneumotórax artificial, que consistia em uma injeção de ar ou substâncias inertes na cavidade pleural, para pressionar o pulmão afetado e diminuir sua movimentação. Acreditava-se que o repouso mecânico induzido e a conseqüente redução da atividade pulmonar poderiam propiciar a morte do bacilo, favorecendo a cura. Embora doloroso e apesar do risco de efeitos colaterais, o pneumotórax era relativamente simples de executar e pôde ser difundido até mesmo em nível ambulatorial. No entanto, o procedimento exigia do paciente uma reserva material que lhe permitisse usufruir repouso, boa alimentação e acompanhamento médico continuado, além de disciplina e vontade para superar as inconveniências de um procedimento invasivo. E essas exigências acabaram por reduzir o número de pessoas que de fato se be- 
neficiaram do método. Poucos anos depois, introduzia-se mais um recurso profilático, cuja distribuição também foi implementada pelos dispensários. Trata-se da vacina BCG (bacilo de Calmette e Guérin), então administrada via oral, que começou a ser produzida em 1927 pelo Instituto Vital Brasil, no Rio de Janeiro, apesar das dúvidas sobre sua eficácia na prevenção da doença.

O funcionamento dos dispensários no coração das principais cidades brasileiras teve sua contrapartida na instalação dos sanatórios, recurso no qual se investia grande expectativa para a cura dos tuberculosos. Além de reduzir o contágio, acreditava-se que a hospitalização possibilitaria melhorar a alimentação e amplificar os efeitos de um acompanhamento médico prolongado. Para essa finalidade, a Liga Brasileira contra a Tuberculose criou um fundo especial de recursos, que culminou na instalação do Preventório Rainha Dona Amélia, em 1927, na Ilha de Paquetá, instituição dedicada a acolher crianças classificadas nas estatísticas escolares como estando em estado de pré-tuberculose e evitar que elas desenvolvessem a enfermidade.

O reconhecimento internacional dos efeitos benéficos da altitude sobre a evolução da moléstia, levou ao estabelecimento de sanatórios na serra da Mantiqueira. No estado de São Paulo, Emílio Ribas, diretor do Serviço Sanitário durante os primeiros anos do século, promoveu a instalação de infra-estrutura urbana e de transportes nas cidades de São José dos Campos e Campos do Jordão, visando ao recolhimento dos doentes do peito. Nos sanatórios, os internos eram submetidos a um rígido esquema disciplinar, higiene, repouso, alimentação e ar puro, e o acompanhamento médico dos internos podia perdurar por vários anos. Os sanatórios para tuberculosos são um advento do século XX e perduraram até os anos 60, quando começaram a ser superados, como concepção terapêutica e de controle da doença, pela difusão dos tratamentos ambulatoriais.

A vida no interior de um sanatório nos Alpes foi retratada por Thomas Mann (1984), em seu conhecido livro Montanha mágica. Com a doença e a Primeira Guerra Mundial como panos de fundo, o autor explorou a educação moral de um jovem, sublinhando a possibilidade do humanismo em tempos de adversidade. A repercussão desse romance foi enorme e suas imagens dominaram nossa compreensão dos significados associados à estada nos sanatórios. Rothman (1994), no entanto, considerou injusto que a qualificação de mágica fosse aplicada a uma situação em que os sentimentos dominantes eram a infelicidade, o desapontamento e o desespero. Segundo ela, em oposição à narrativa, a maioria dos doentes seria desprovida de recursos materiais para usufruir os benefícios da hotelaria, sofrendo também privações quanto à qualidade e quantidade dos serviços médicos recebidos. Nesse sentido, a internação no sanatório, para grande parte dos tuberculosos, refletiria mais proximamente a experiência prisional de uma instituição total, conforme a conhecida caracterização de Goffman (1987). Uma antecâmara da morte, na qual a cura, embora possível, parecia distanciar-se com insistência.

No Brasil, uma novela escrita em 1949 por Dinah Silveira de Queiroz (1988) também abordou o cotidiano da vida sob o regime de isolamento. Valendo-se do recurso estilístico de nunca nomear a doença que move a narrativa, ou cedendo ao preconceito usual de evitar o termo insidioso, Floradas na serra descreveu de modo cinematográfico o amadurecimento emocional de adolescentes recolhidas em uma pensão para moças, em Campos do Jordão. Embora a introdução da estreptomicina (o primeiro antibiótico de grande impacto sobre a tuberculose) na prática clínica houvesse se iniciado em 1947, esse livro foi escrito ainda sob a égide do reconhecimento da tuberculose como doença praticamente incurável.

Somos então informados que as floradas dos pessegueiros, cuja coloração rosada lembrava o linho branco dos lenços tingidos de sangue, coincidiam com a estação mais propícia às hemoptises. Acompanhamos a morte surpreendendo crianças e jovens e, como Manuel Bandeira (1987), testemunhamos febre, hemoptise, dispnéia e suores noturnos, a vida inteira que podia ter sido e que não foi. Tentando preservar os padrões de sociabilidade da vida sadia, a cidade inteira havia praticamente se convertido em um imenso sanatório; pois, além dos asilos e hospitais ali instalados, diversas pensões recebiam doentes abastados do Rio de Janeiro e de São Paulo, e até às residências se convidava o aluguel de vagas aos enfermos.

Em um trabalho de especial impacto inclusive no meio médico, Susan Sontag (1984) reconstituiu os processos históricos através dos quais se produziu toda uma mitologia cercando a tuberculose e denunciou o excesso de sofrimento suscitado pela associação de metá- 
foras com a realidade biológica da doença. Guerrand (1985) também sublinhou o contraste entre a concepção romântica da doença, que teria prevalecido até o início do século, e a percepção posterior do perigo público representado pelo proletário portador de germes. Conquanto alguns doentes do peito - como Álvares de Azevedo, Noel Rosa e Manuel Bandeira - apresentavam certos caracteres dos quais o gênio parecia tirar partido, era muito reduzida a parcela da população que teria acesso ao paraíso de pinheirais dos sanatórios em expansão.

Existe, contudo, na literatura nacional, uma crua descrição da vida sanatorial, bastante despojada das idealizações com que se revestiu a tuberculose. Em um livro de memórias, Nelson Rodrigues relatou sua própria experiência asilar, por ocasião de seu internamento em Campos do Jordão, no período de abril de 1934 a junho de 1935. Embora houvesse sido encaminhado como indigente, preferiu pagar os honorários do estabelecimento, para evitar a obrigação dos serviços cobrados a esta categoria de doentes: varrer, mudar a roupa de cama e, ainda por cima, servir à mesa (Rodrigues, 1994). Apesar de reduzida, a taxa cobrada somava-se às despesas relativas aos exames laboratoriais de controle do tratamento, consumindo a quase totalidade de seus vencimentos como jornalista de $O$ Globo, afastado para o tratamento.

Mesmo para os pagantes, o sanatório não disponibilizava facilidades ou confortos especiais. Era a casa dos mortos (Rodrigues, 1994). Sua cama ficava debaixo de uma janela que nunca podia ser fechada, apesar do tradicional frio das noites na cidade. Seu quarto era uma enfermaria partilhada por outros doentes, que juntos produziam uma fauna misteriosa e tristíssima de tosses. A rotina diária era marcada pela regularidade dos horários e a disciplina do estabelecimento não tolerava modificações. Os caixões eram despachados durante a madrugada, para não deprimir os internos, lembrando-lhes o feio destino comum. Nessas condições, ele pôde conviver com doentes ali internados há anos, alguns mutilados pela toracoplastia - intervenção cirúrgica coadjuvante da terapêutica antituberculose, que consistia na retirada de costelas e conseqüente redução da cavidade torácica -, recolhendo fragmentos de suas reclamações.

O autor também se queixava das cartas de parentes e amigos, que minguavam já no pri- meiro mês e desapareciam logo em seguida: Ainda não morri e já me esqueceram (Rodrigues, 1994). Visitas, então, sequer eram esperadas. Reconhecemos o valor que os internos atribuíam à possibilidade de morrer em casa. Acompanhamos várias passagens em que homens em plena maturidade testemunhavam a insatisfação com a abstinência sexual forçada: O tuberculoso de hoje, salvo os casos agudos, namora, casa, beija. Naquela época, havia o pavor do contágio. (...) Beijo era contágio maciço (Rodrigues, 1994).

Embora tivesse voltado para o Rio de Janeiro supostamente curado, Nelson Rodrigues teve várias recaídas nos anos seguintes, perdeu parte da visão como decorrência da tuberculose e retornou mais três vezes a Campos do Jordão, sofrendo seguidas aplicações do pneumotórax. Castro (1995) contabilizou em quinze anos sua experiência com a doença, até que, enfim em 1949, a estreptomicina ter-lhe-ia curado definitivamente.

\section{O hábito de escarrar e as escarradeiras}

O que é que os cortiços tiveram em comum com as salas de visitas das casas mais abastadas? O que é que os teatros e restaurantes tiveram em comum com as fábricas? As igrejas com as casas onde se ia exercer a libertinagem? Acertou quem respondeu um bacião com aba coletora, no interior do qual se despejava uma solução anti-séptica, para servir de alvo e pontaria ao exercício de escarrar em público. Durante muito tempo, a escarradeira dividiu espaço na planta baixa das edificações com outro objeto decorativo, cujo uso também se refere a hábito anti-higiênico e que só recentemente começou a desaparecer dos prédios públicos: o cinzeiro com fundo de areia. Nos ambientes mais humildes, uma única peça teria cumprido as duas finalidades.

Em uma extensa pesquisa envolvendo escavações arqueológicas em depósitos de lixo doméstico no Rio de Janeiro do século XIX, Tânia Andrade Lima (1996) reportou o achado de diversas escarradeiras de faiança, porcelana, vidro e metais nobres, com formas e estampas rebuscadas, peças que hoje encontram espaço nos museus e lojas de antigüidades. Segundo ela, os artefatos destinados a aparar o excesso de saliva e catarro confirmam a impregnação da mentalidade, nos séculos XVIII 
e XIX, pelo humorismo hipocrático. Inusitado para os padrões atuais, o ato de expelir o catarro atestaria a extrema importância em não reter aquilo que se considerava nocivo ao organismo. Para que essa prática fosse exercida sem qualquer constrangimento, teria sido transformada em um hábito não apenas socialmente tolerado, mas sobretudo elegante. Desse modo, teriam sido criados recipientes requintados para receber os fluidos viscosos, os quais marcaram presença nos ambientes públicos e privados.

Se originariamente a escarradeira teve sua difusão associada a comportamentos obsessivos - cuspir e mascar tabaco -, com o tempo, viria a configurar mais um signo dos esforços coletivos no combate à tuberculose. Nesse sentido, é interessante notar que, mesmo em um período em que ainda eram pouco intensos os esforços oficiais de combate à tuberculose, as primeiras menções legislativas visando à profilaxia da doença estivessem justamente dirigidas à obrigatoriedade do uso das escarradeiras.

Entre 1899 e 1904, diversas leis e resoluções normativas foram promulgadas, determinando várias obrigações relativas ao controle da tuberculose: notificação compulsória; desinfecção domiciliar em casos de óbito pela enfermidade; proibição do costume de cuspir no chão e no interior dos veículos do transporte público; isolamento dos doentes nos hospitais; sua retirada dos cortiços; proibições quanto ao exercício profissional do comércio; aplicação de provas tuberculínicas nos animais de estábulos. Esses primeiros dispositivos legais, no entanto, teriam sido inócuos, por um lado, pela falta de ação efetiva do poder público, que não teria a doença como alvo prioritário, por outro, pela precária condição socioeconômica do grupo populacional mais vulnerável à enfermidade (Nascimento, 1991). A despeito da falta de repercussão efetiva dessas medidas, é interessante notar que a colocação de escarradeiras em habitações coletivas e logradouros públicos foi diversas vezes reiterada nesses documentos legais.

Através de múltiplas aparições na imprensa médica, Afrânio Peixoto explicava a compreensão corrente dos motivos que teriam justificado a difusão do utensílio. Para cada doente que morria de tuberculose, ter-se-ia sete pessoas transmitindo e disseminando a moléstia (Peixoto, 1922). Em se tratando de uma doença transmitida por via respiratória e havendo muitas pessoas atuando como fontes de infecção mesmo antes que se estabelecesse a suspeita clínica de tuberculose, seria importante que todos se habituassem a uma série de preceitos de asseio pessoal, para obstar o contágio. A emissão de gotículas bacilíferas através da fala, riso, bocejo, tosse e espirro deveria contemplar o uso constante do lenço e da distância pessoal durante as conversas (Peixoto, 1902b). O hábito de cuspir no chão deveria ser combatido em função dos tantos milhões de bacilos de Koch que um só escarro pode abrigar (Peixoto, 1902d). Uma vez expelido, o escarro ressecava-se, podendo ser espalhado pelo ar através dos sapatos, veículos, animais e até dos longos vestuários femininos que se arrastavam pelo chão.

Considerando a necessidade pessoal em não reter os humores e o risco para a saúde coletiva existente em sua livre deposição, o uso das escarradeiras era tido como solução para o muito temido problema da transmissão da tuberculose. Apesar disso, a pregação contrária às escarradeiras também teve início nesse período, e Afrânio Peixoto acusava o utensílio de contribuir antes à causa inversa, ajudando a promover a disseminação da moléstia. Segundo ele, dever-se-ia substituir o artefato pelos escarradores portáteis, de bolso, utensílio bastante empregado nos sanatórios: Entre nós os luxuosos ou modestos escarradores que existem são os aparelhos de faiança, de vidro, de metal pousados a chato sobre assoalhos ou tapetes, recebendo de longe o escarro que se lhes projeta: bem merecem o epigrama referido por Knopfsão vasos de flor em redor dos quais se escarra... Quando o escarro não cai fora das bordas, fixase nas paredes afuniladoras do vaso, desseca-se, contamina milhares de moscas que ali vêm pousar e nos transmitir depois às roupas, aos cabelos, à pele, aos alimentos os germes recolhidos em profusão (Peixoto, 1902c).

$\mathrm{O}$ autor lembrava que as duas Faculdades de Medicina, no Rio de Janeiro e na Bahia, praticamente já haviam abolido as escarradeiras de uso comum, apenas dispondo do artefato para os momentos solenes, nas salas de cerimônias. E até mesmo nessa circunstância, a sujeira do utensílio mantido sob vigilância médica seria indicativo do muito que ainda haveria a ser feito pela educação higiênica do povo.

Pierre Darmon também apontou uma série de inconvenientes sanitários relacionados ao hábito de escarrar e ao uso das escarradeiras. Esses objetos eram pesados e difíceis de manipular. Ademais, ao contrário dos urinóis, 
eram desprovidas de alça, indicando que não seriam removidas do chão com freqüência, para despejo e lavagem, o que decerto provocaria mau cheiro no ambiente. A solução de ácido fênico despejada em seu interior, além de tóxica, exalaria um cheiro insuportável que provoca náuseas e acessos de tosse (Darmon, 1985).

Nos ambientes menos sofisticados, por economia, o líqüido anti-séptico era substituído por resíduos sólidos, como areia, serragem e cinzas, o que dificultava seu esvaziamento e favorecia a dispersão aérea de muco ressecado. Os escarros secos seriam mais perigosos que os úmidos, nos quais os bacilos permaneceriam aglutinados, havendo múltiplas ocasiões para se produzir o aerossol venenoso. A falta de pontaria ou a dificuldade em se abaixar para se aproximar do alvo, o vento e a vassoura vinham se somar a outros comportamentos de risco para a doença: o costume de lamber selos, mordiscar a extremidade de uma caneta, umedecer a ponta dos dedos para folhear papéis, a partilha dos cigarros, beijar as imagens santas (Peixoto, 1902a; Chateau, 1906a) e até servir-se de água benta (Carvalho, 1899; Chateau, 1906b). E todos esses fatores contribuiriam para se atingir números cabalísticos: sete milhões de bacilos diariamente expectorados por cada tuberculoso, um sétimo do gênero humano cujas vidas ceifava a tuberculose.

Apesar das pregações em contrário, as escarradeiras continuariam presentes nos logradouros públicos por muitos anos, marcando época nos esforços coletivos voltados à luta contra a tuberculose. Em uma crônica, publicada em 1967, no jornal O Globo, Nelson Rodrigues atestava o quão fortemente as escarradeiras haviam se impresso à mentalidade de toda uma geração: O brasileiro cospe menos, diria eu. Quanto às nossas mulheres, nem cospem. Mas no tempo do fraque e do espartilho, a cidade expectorava muito mais. Lembro-me de antigas bronquites, de tosses longinquas, asmas nostálgicas. Nas salas da Belle Époque era obrigatória esta figura ornamental: - a escarradeira de louça, com flores desenhadas em relevo (e pétalas coloridas) (Rodrigues, 1995).

\section{A abreugrafia nasceu aqui...}

Nos anos 60 e 70, uma obrigação sanitária relacionada à tuberculose acompanhou diversos passos da vida civil. A criança vai entrar na escola? O jovem vai solicitar a emissão da carteira de trabalho? O adulto vai trocar de emprego? Então são todos candidatos a uma abreugrafia. De posse do registro fotográfico da imagem radiológica dos pulmões, o interessado comprava um selo médico em bancas de jornal, juntava o certificado de vacinação contra a varíola e levava toda essa documentação para apreciação do médico que emitiria o atestado de saúde. Esse certificado foi requisito associado principalmente às obrigações trabalhistas, na admissão e controle periódico de saúde dos trabalhadores, sendo inclusive requisito para o ingresso em algumas escolas.

Disposições legislativas do período, como a lei no 6.514/77, repassaram o ônus desses exames do interessado para o empregador. Desse modo, dividia-se o custo da abreugrafia, desonerando em parte o serviço público, que desde meados do século procurou ampliar sua realização, como estratégia de busca ativa de casos da tuberculose, não só com a preocupação de assistência ao paciente, mas também para tentar interromper ou ao menos diminuir a intensidade da transmissão. Naqueles anos, o uso da abreugrafia esteve tão difundido nas principais cidades brasileiras, que havia inúmeras clínicas radiológicas oferecendo esse serviço contra o pagamento de honorários. Ajudando a incrementar a impressão da abreugrafia sobre o imaginário social, esses estabelecimentos contratavam aposentados e desempregados para distribuir panfletos e divulgar o serviço, carregando placas nas ruas mais movimentadas.

Mas não foi apenas a vida civil que se valeu do método. Haygood e Briggs (1992) reportaram que, conquanto os soldados recrutados para a Primeira Grande Guerra tivessem sido avaliados clinicamente apenas pelo exame físico pessoal, a técnica desenvolvida no Brasil tornara possível o screening radiográfico em massa dos soldados e marinheiros conduzidos à Segunda Guerra Mundial. Esse procedimento também teria inspirado um ambicioso programa de busca de casos de tuberculose entre os norte-americanos, abrangendo o exame de cerca de dez milhões de pessoas no período.

A julgar pelo ufanismo impresso em artigos de divulgação (Fiorino, 1992; Santos, 1976), teria sido de fato motivo de orgulho nacional: a abreugrafia nasceu no Brasil! Em 1936, o médico brasileiro Manoel Dias de Abreu (18921962) desenvolveu um método combinando 
radiografia e fotografia para efetuar o rastreamento da tuberculose pulmonar, cuja aplicação também poderia evidenciar sinais de câncer e cardiopatias. Acompanhando a onda nacionalista do período e com o intuito de difundir sua aplicação, o decreto no 42.984/58, promulgado pelo presidente Juscelino Kubitschek, reservava o 4 de janeiro como dia da abreugrafia.

O mérito do procedimento residia na simplificação e redução de custos da radiografia convencional, o que permitiria sua aplicação em larga escala. A técnica consistia na obtenção de uma fotografia da imagem que aparece na radioscopia do tórax, motivo pelo qual seu criador denominou-lhe roentgenfotografia ou fluorografia. Apesar dos termos propostos, o I Congresso Nacional de Tuberculose, realizado no Rio de Janeiro em 1939, tornaria oficial o nome de "abreugrafia", conceito posteriormente ratificado pela União Internacional contra a Tuberculose.

Campos (1965) apresentou dados demonstrando a crescente incorporação da abreugrafia aos serviços públicos de saúde. Entre 1946 e 1956, o número de dispensários brasileiros teria aumentado de 20 para 87 , enquanto o número de exames radiológicos anuais teria passado de pouco menos de cem mil para cerca de um milhão. Entre 1952 e 1963, a quantidade de brasileiros submetidos anualmente ao método teria mais que dobrado, crescendo de 1,05 para $2,25 \%$ do total da população. Esses indicadores continuaram em expansão até meados dos anos 70 (Figueiredo, 1978).

Apesar da grande expectativa depositada na abreugrafia, logo se previu problemas para a generalização do método e não foram poucas as críticas contrárias a sua aplicação. Logo após a proposição do método, Covelo Júnior (1939) já chamava atenção para as dificuldades em estender serviços a um número potencialmente crescente de casos suspeitos de tuberculose que seriam evidenciados pela radiologia, numa sociedade que sofria fortes restrições econômicas e estava praticamente desprovida de serviços efetivos de saúde. Além disso, ele colocava em questão a falta de especificidade do método e as dificuldades relativas ao encaminhamento dos casos duvidosos.

Em 1948, Certain acusava os excessos na aplicação indiscriminada da abreugrafia e solicitava sua abolição em menores de dois anos de idade, em função da reduzida especificidade do método nesses casos, apesar de ainda não prevalecer na mentalidade médica a consciência dos riscos relativos à exposição do organismo à radiação. Em 1962, Paula Souza et al. sublinhavam o mau desempenho da abreugrafia também para menores de 15 anos, recomendando que ela fosse apenas indicada aos indivíduos desse grupo que houvessem apresentado teste tuberculínico positivo. Em 1965, Oswaldo Campos avaliava que o cadastro torácico não teria alcançado grande penetração em nosso meio, em função do baixo rendimento das unidades que prestavam o serviço e das dificuldades em controlar uma população irregularmente distribuída em grande extensão territorial. E, no final da década de 1970, o Programa Nacional de Controle da Tuberculose substituiu a abreugrafia pela realização sistemática da baciloscopia em sintomáticos respiratórios, exame de menor custo e mais fácil de operacionalizar, como estratégia de rastreamento de tuberculosos.

A partir desse período, vários dispositivos legais suspenderam a obrigatoriedade da abreugrafia como requisição generalizada para assintomáticos. Em São Paulo, a Delegacia Regional do Trabalho cancelou a exigência da abreugrafia nos exames médicos admissional e demissional de empregados em 1984, antes mesmo que fosse modificado o Artigo 168 da Consolidação das Leis do Trabalho - CLT, atendendo a orientação do Ministério do Trabalho para todo o país.

Em 1985, a Secretaria Estadual da Saúde de São Paulo determinou que a abreugrafia não mais fosse exigida para o fornecimento dos atestados de saúde. Para fundamentar essa decisão, ponderava-se a existência de novas técnicas de diagnóstico da tuberculose melhor adequadas à nossa realidade; que a eficácia dos tratamentos disponíveis e o aprimoramento de outros instrumentos aplicados ao controle da doença não mais justificariam o exame radiológico em massa, inclusive pelos riscos associados à exposição continuada a repetidas doses de radiação. Além disso, o documento legal ponderava que os serviços abreugráficos haviam proliferado de "forma caótica, aberrante e incontrolável" em nosso meio (São Paulo, 1985).

Por fim, em 1990, o Ministério do Trabalho e Previdência Social excluiu a abreugrafia do conjunto de exames médicos obrigatórios de acompanhamento da saúde do trabalhador e revogou as disposições em contrário (Brasil, 1990). 


\section{O significado social da doença: mutações}

A projeção da tuberculose no Brasil ao longo do século caracteriza-se por modificações tão profundas, que quase se poderia dizer não existir uma única figura nosológica para descrever a doença. A tuberculose, se analisada quanto a seu comportamento na comunidade, é hoje uma doença diferente daquela conhecida há pouco mais de cinqüenta anos. Seu diagnóstico ganhou recursos tecnológicos; seu tratamento passou a implicar prescrições diferentes; modificou-se o perfil da população por ela afetada. O risco de contágio também se alterou, a possibilidade de cura tornou-se efetiva e até as metáforas associadas à doença foram renovadas. É interessante notar que a transição da tuberculose entre seus diferentes perfis acompanhou de perto as mudanças de atitudes das políticas governamentais de combate à enfermidade, bem como as modificações nas formas sociais de representação da doença.

Para caracterizar essas mutações, a análise epidemiológica fornece importantes indicações. Essa tarefa, contudo, é dificultada pelo reduzido número de estudos nessa área e pela insuficiência de dados com abrangência nacional. Até os anos 70, poucas cidades dispunham de um sistema consistente de informações de mortalidade e, apesar da notificação da tuberculose ter sido compulsória desde o início do século, não são disponíveis registros confiáveis de morbidade para todo o período. No entanto, para São Paulo e Rio de Janeiro, que concentraram parcela ponderável da população urbana brasileira até meados deste século, foram traçadas séries temporais de mortalidade por tuberculose com razoável margem de confiabilidade, permitindo uma boa impressão da magnitude e das tendências da doença (Antunes \& Waldman, 1999; Penna, 1988).

Durante toda a primeira metade do século, a doença caracterizou-se por elevadas taxas de mortalidade e foi uma das principais causas de óbito nas capitais brasileiras, em geral somente suplantada pelas diarréias e pneumonias. Estima-se que a tuberculose tenha respondido nesse período por quase $10 \%$ do total de óbitos ocorridos em São Paulo, com valores ainda mais elevados para o Rio de Janeiro. A estrutura etária desses óbitos acompanhou os padrões observados nos países de alta prevalência, com coeficientes mais elevados para os menores de 5 anos de idade, entre 20 e 49 anos e 60 anos ou mais, com predomínio do grupo de 20 a 49 anos. Em contraste com a maior prevalência da tuberculose no sexo masculino, observada no período mais recente, a mortalidade devida à doença distribuíase com relativa eqüidade entre mulheres e homens (Galesi, 1999).

A partir do final dos anos 40 , a tuberculose passou a apresentar um panorama distinto. A mortalidade experimentou persistente e acentuado declínio, fator que se pode atribuir à introdução de novas armas tecnológicas e ações de controle. A tendência decrescente da mortalidade, contudo, não foi acompanhada na mesma intensidade pela redução do número de casos novos da doença (Penna, 1988). Desse modo, observou-se um efeito paradoxal: conquanto se reduzia a letalidade da tuberculose, sua prevalência se elevou nas principais cidades. Com o passar dos anos, novos fatores vieram a interagir para a mudança no perfil epidemiológico da moléstia. Por um lado, assistiu-se a diversas melhorias sociais, as quais se refletiram em diferentes indicadores sociais, econômicos e de saúde e possibilitaram, inclusive, a expansão da assistência médica oferecida pela previdência social aos trabalhadores. Todavia, assistiu-se também ao início de um rápido e desumano processo de urbanização da população brasileira e migrações desordenadas, fatores de retardo na queda de incidência da tuberculose, em possível sinergia com a baixa efetividade dos serviços especificamente dirigidos ao controle da doença.

Nesse período, também se observou a modificação da distribuição etária da tuberculose, com acentuada diminuição da morbi-mortalidade em menores de 5 anos, principalmente a partir de meados dos anos 70, coincidindo com a ampliação da cobertura do BCG intradérmico para menores de um ano (Almeida, 1990). Já em meados dos anos 80 , a mortalidade devida à tuberculose nessa faixa etária reduziu-se a ponto de deixar de configurar problema relevante em saúde pública nas grandes cidades. Também se reduziu o coeficiente de mortalidade por tuberculose no grupo de 20 a 49 anos de idade e, apesar de terem mantido valores elevados, esse grupo foi progressivamente perdendo importância em relação aos maiores de 60 anos.

A trajetória da endemia no Brasil observou diferenças de curso com os países industrializados, nos quais, a mudança epidemio- 
lógica da tuberculose efetuou-se num período anterior. Nesses países, após atingir patamares muito elevados durante o início da revolução industrial, a tendência de declínio da enfermidade começara já na primeira metade do século XIX. Antes mesmo da era microbiológica, sua incidência e mortalidade decresceram principalmente em função da melhora acentuada nas condições de vida. A introdução da quimioterapia, a partir dos anos 40, determinou nesses países impacto menos importante do que o verificado nas regiões não industrializadas (Dubos \& Dubos, 1996) e mesmo a vacina BCG não foi amplamente utilizada nos países da Europa e América do Norte.

O período marcado pela mortalidade mais elevada (até os anos 40) correspondeu, no Brasil, à quase completa inação dos órgãos e serviços públicos de saúde, os quais estiveram prioritariamente engajados na atenção a doenças epidêmicas de maior interesse para a política econômica. Nessa fase, a tuberculose praticamente só foi contemplada por esforços benemerentes e iniciativas privadas, que não alteraram a trajetória de sua morbi-mortalidade. No que diz respeito à inserção da tuberculose no imaginário social, enquanto não melhorou o prognóstico da doença, prevaleceram as metáforas da fatalidade e da provação que soergue o espírito.

No período seguinte, em que a redução da mortalidade foi acompanhada pela polarização da doença nos estratos sociais mais submetidos à privação, assistiu-se à intensificação da intervenção estatal dirigida à doença. Quanto à mentalidade, passaram a prevalecer os conceitos dos riscos associados às más condições de vida e do perigo público representado pela pobreza como fator de disseminação da moléstia. A produção de metáforas associadas à doença deslocou-se da consumpção, do sofrimento idealizado, para os terrores da degradação física e social. Nesse sentido, o incremento da intervenção estatal nos programas de combate à tuberculose parece ter acompanhado de perto o medo do contágio nas relações interpessoais envolvendo classes sociais distintas, em especial nas interações propiciadas pelo trabalho.

A partir de 1985, à semelhança do que ocorreu em diversos países, a tuberculose passou a sofrer um importante incremento na mortalidade, apesar de dados oficiais de morbidade indicarem a estabilidade da incidência em patamares elevados (cerca de 60 a 70 casos novos por 100.000 habitantes a cada ano). Vale salientar que, a partir desse período, os indicadores de saúde apresentaram sensível melhora em nível nacional (Monteiro, 1995), criando um descompasso entre a trajetória da tuberculose e das demais doenças infecciosas incluídas na agenda tradicional de prioridades em saúde pública. As elevadas taxas de mortalidade por tuberculose, característica ainda presente no país, parecem refletir a reduzida efetividade dos serviços de saúde, os quais, apesar de terem atingido coberturas apreciáveis nos últimos 15 anos, não foram capazes de oferecer um serviço com a regularidade e qualidade necessárias para romper a cadeia de transmissão da tuberculose.

Supõe-se que a elevação da mortalidade por tuberculose, nesse período, tenha refletido sobretudo o aumento da co-infecção entre microbactérias e o vírus da imunodeficiência humana - HIV. A Organização Mundial da Saúde avaliou, para a realidade brasileira, que a co-infecção pelo HIV houvesse atingido 10\% dos casos de tuberculose (WHO, 1997). Ruffino-Netto (1995), numa estimativa preliminar, apontava taxa ainda mais elevada: $17,7 \%$. A queda observada na mortalidade por tuberculose nos anos de 1996 a 1998, de certa forma acompanhando semelhante declínio na mortalidade por AIDS, dá consistência a essa hipótese.

Acredita-se que para o descompasso observado entre o aumento da mortalidade e a estabilização em níveis elevados da incidência da tuberculose, teria convergido a possível diminuição de sensibilidade da vigilância, sem a concomitante alteração desse atributo no sistema de informação de mortalidade. Outra observação relevante para explicar o crescimento da mortalidade por tuberculose nesse período refere-se ao possível aumento de circulação de cepas resistentes aos agentes quimioterápicos. A esse respeito, a Organização Mundial da Saúde estima que, no Brasil, 9\% dos doentes de tuberculose alberguem bacilos resistentes à isoniazida, à rifampicina, ao ethambutol ou à estreptomicina, enquanto $1,3 \%$ apresentariam resistência combinada a dois ou mais dos recursos medicamentosos, indicando a tão temida contaminação por cepas multi-drogas resistentes (WHO, 1997).

Analisando as novas feições que a tuberculose vem assumindo não apenas nos meios científicos, mas no imaginário social, Katherine Ott (1996) afirmou que ainda é cedo pa- 
ra saber quais caracteres da doença serão lembrados quando no futuro se quiser revisitar o momento presente. Propôs, no entanto, que se evitasse a reprodução de estigmas e a elaboração de novas metáforas para a doença. Procurava, em especial, evitar a transposição para a cultura popular da caracterização epidemiológica da tuberculose como doença reemergente, receando que isso viesse a obscurecer o significado da doença para aqueles que a vivenciam no período recente. Segundo a autora, essa proposição eludiria o fato de a moléstia haver mantido elevada sua incidência em praticamente todo o mundo, durante o século inteiro. Até mesmo nos países industrializados, nos quais se observaram avanços mais expressivos na redução da tuberculose, a doença manteve-se como motivo de constante preocupação para determinados grupos de população, como idosos, pobres, migrantes e povos nativos dos países da América. Nesse sentido, referir a doença como reemergente traria implícita uma idealização da miraculosa capacidade de intervenção da ciência e tecnologia médicas, a qual não corresponderia à realidade e pressuporia subestimar a real dimensão da tuberculose no período precedente.

A caracterização de algumas doenças como reemergentes é uma nova abordagem para descrever o comportamento de doenças infecciosas e se refere ao reaparecimento de algumas dessas enfermidades após um período de declínio significativo, como ocorreu com o có- lera e a dengue, no Brasil. A aplicação desse conceito à tuberculose poderia encontrar pertinência como elemento de realce da retomada do movimento ascendente da mortalidade e reforço da reivindicação de recursos e prioridades para as tarefas voltadas ao seu controle. No entanto, até mesmo no campo da análise epidemiológica, a caracterização da tuberculose como doença reemergente não é ponto pacífico. A esse respeito, o Coordenador $\mathrm{Na}$ cional de Pneumologia Sanitária afirmou enfaticamente que a tuberculose não é doença remergente. É doença que sempre esteve presente e permanece. (...) Longe pensar que a tuberculose foi erradicada no Brasil. Nunca chegamos a uma redução significativa de sua magnitude a ponto de não considerá-la mais um problema (Ruffino-Netto, 1998).

A tuberculose não é reemergente para aqueles que a estiveram sofrendo e foram marginalizados em decorrência da doença ao longo de toda a sua vida (Ott, 1996). Superestimar o impacto da tecnologia é injusto para as muitas pessoas que não puderam ter atendidas suas expectativas quanto a tratamentos e prevenção. A crença insuflada nos poderes excepcionais e superiores da tecnologia médica não contribuiria para o cumprimento de suas elevadas promessas e tampouco impediria a repetição reiterada de nosso profundo desapontamento. A tuberculose não acabou, nunca foi erradicada e dificilmente deixará de ser motivo de preocupação para nossos filhos e netos.

\section{Agradecimentos}

À senhora Marília March, da Casa de Oswaldo Cruz, Fiocruz, Rio de Janeiro, pelo apoio à reunião de literatura para o presente estudo.

\section{Referências bibliográficas}

Almeida MMMB 1990. Vigilância epidemiológica da tuberculose no município de São Paulo: uso de dados de mortalidade. Tese de doutorado. Faculdade de Saúde Pública, Universidade de São Paulo. 142pp.

Antunes JLF \& Waldman EA 1999. Tuberculosis in the twentieth century: time-series mortality in São Paulo, Brazil, 1900-97. Cadernos de Saúde Pública 15(3): 125-138.

Bandeira M 1987. Estrela da vida inteira. José Olympio Editora, Rio de Janeiro. 449pp.

Barreira IA 1993. A enfermeira Anna Nery no "país do futuro": a aventura da luta contra a tuberculose. Dissertação de mestrado. Escola de Enfermagem Anna Nery, Universidade Federal do Rio de Janeiro. 335pp.

Bertolli Filho C 1992. História social do tuberculoso: perspectivas documentais. Cadernos de História e Saúde 2:42-50. 
Bertolli Filho C 1993. Historia social da tuberculose e do tuberculoso:1900-1950. Tese de doutorado. Faculdade de Faculdade de Filosofia, Letras e Ciências Humanas, Universidade de São Paulo. 2v.

Brasil 1990. Ministério de Estado do Trabalho e da Previdência Social. Portaria no 3.720, de 31 de outubro de 1990. Diário Oficial da União, 1o de novembro de 1990.

Campos O 1965. Contribuição para o planejamento da luta antituberculose no Brasil. Tese de doutorado. Faculdade de Higiene e Saúde Pública, Universidade de São Paulo. 289pp.

Carvalho AV 1899. Água benta, veículo de infecção. Gazeta Médica da Bahia 30:35-38.

Castro R 1995. O anjo pornográfico: a vida de Nelson Rodrigues. Companhia das Letras. São Paulo. 457pp.

Certain DA 1948. Da atuação do dispensário de tuberculose da Faculdade de Higiene e Saúde Pública sobre o grupo etário 0-2 anos, desde 1938 até dezembro 1947 (10 anos). Tese de livre-docência. Faculdade de Higiene e Saúde Pública, Universidade de São Paulo. 140pp.

Chateau O 1906a. O beijo nas imagens. Gazeta Médica da Bahia 37:337-342.

Chateau O 1906b. A higiene nas igrejas. Gazeta Médica da Bahia 37:382-384.

Covelo Júnior M 1939. A propósito da roentgenfotografia, pp. 147-152. I Congresso Nacional de Tuberculose, vol. 1. Rio de Janeiro.

Darmon P 1985. É proibido escarrar, pp. 249-253. In Le Goff J (org.). As doenças têm história. Ed. Terramar, Lisboa.

Dubos R \& Dubos J 1996. The white plague: tuberculosis, man, and society. Rutgers University Press. New Brunswick. 277pp.

Fernandes TAL (coord.) 1993. Memória da tuberculose: acervo de depoimentos. Casa de Oswaldo Cruz, Fiocruz e Coordenação Nacional de Pneumologia Sanitária da Fundação Nacional de Saúde, Rio de Janeiro. $103 \mathrm{pp}$.

Figueiredo DP 1978. Aqui nasceu a abreugrafia, pp. 133137. Anais das Atividades da Associação Brasileira de Arquivo Médico e Estatística - ABAME. Rio de Janeiro.

Fiorino AR 1992. Manoel de Abreu (1892-1962). Revista Argentina del Torax 53(3-4):86-91.

Galesi VMN 1999. Mortalidade por tuberculose no município, análise de uma década, 1986 a 1995. Dissertação de mestrado. Faculdade de Saúde Pública, Universidade de São Paulo. 112pp.

Goffman E 1987. Manicômios, prisões e conventos. Ed. Perspectiva, São Paulo. 312pp.

Guerrand RH 1985. Guerra à tuberculose, pp. 187-201. In Le Goff J (org.). As doenças têm história. Ed. Terramar, Lisboa.

Haygood TM \& Briggs JE 1992. World War II military led the way in screening chest radiography. Military Medicine 157(3):113-116.

Lima TA 1996. Humores e odores: ordem corporal e ordem social no Rio de Janeiro, século XIX. História, Ciências, Saúde - Manguinhos II(3):44-96.

Mann T 1984. Montanha mágica. Ed. Nova Fronteira, Rio de Janeiro. 800pp.

Monteiro CA 1995. Velhos e novos males da saúde no Brasil: a evolução do país e de suas doenças. Ed. Hucitec e NUPENS/USP, São Paulo. 356pp.

Nascimento DR 1991. Tuberculose: de questão pública a questão de Estado. A Liga Brasileira contra a Tubercu- lose. Dissertação de mestrado. Instituto de Medicina Social, Universidade do Estado do Rio de Janeiro. 144 pp.

Nogueira O 1950. Vozes de Campos do Jordão. Revista de Sociologia, São Paulo. 170pp.

Ott K 1996. Fevered lives: tuberculosis in American culture since 1870. Harvard University Press, Cambridge e Londres.

Paula Souza R, Certain DA \& Garrafa NAM 1962. Contribuição à posição atual da abreugrafia na profilaxia da tuberculose. Abreugrafia e grupo etário. Arquivos do Instituto Brasileiro de Investigação sobre Tuberculose 21(1-2):36-43.

Peixoto A 1902a. As igrejas. Gazeta Médica da Bahia 33: 326-331.

Peixoto A 1902b. Os lenços e as doutrinas médicas do contágio da tuberculose por inalação. Gazeta Médica da Bahia 33:367-373.

Peixoto A 1902c. Os escarradores. Gazeta Médica da Bahia 33:417-421.

Peixoto A 1902d. Um reparo higiênico sobre o vestuário feminino. Gazeta Médica da Bahia 33: 515-519.

Peixoto A 1922. Um século de cultura sanitária (18221922). Brazil-Médico 36:155-164.

Penna MLF 1988. Tuberculose: assistência ou controle? Discussão sobre a efetividade epidemiológica dos programas de controle baseados no diagnóstico e tratamento de casos. Dissertação de mestrado. Instituto de Medicina Social, Universidade do Estado do Rio de Janeiro. 130pp.

Porto A \& Nascimento DR 1995. Tuberculosos e seus itinerários. História, Ciências, Saúde - Manguinhos I (2):129-141.

Queiroz DS 1988. Floradas na serra. Ed. Record, Rio de Janeiro. 162pp.

Rodrigues N 1994. A menina sem estrela: memórias. Companhia das Letras, São Paulo. 279pp.

Rodrigues N 1995. O óbvio ululante. Primeiras confissões. Crônicas. Companhia das Letras, São Paulo. 303 pp.

Rothman SM 1994. Living in the shadow of death: tuberculosis and the social experience of illness in american history. The Johns Hopkins University Press, Baltimore e Londres. 319pp.

Ruffino-Netto A 1995. Avaliação do excesso de casos de tuberculose atribuídos à infecção HIV/AIDS: ensaio preliminar. Revista de Saúde Pública 29(4):279-282.

Ruffino-Netto A 1998. Tuberculose. Médicos HC-FMUSP 1(3):38-42.

Santos IB 1976. Manoel de Abreu. Arquivos Brasileiros de Tuberculose 35(1-4):17-27.

São Paulo 1957. Secretaria de Estado da Saúde Pública e da Assistência Social. Clemente Ferreira: breves notas biográficas ao ensejo do centenário do nascimento (1857 - 29/9 - 1957) do pioneiro da luta contra a tuberculose no Brasil.

São Paulo 1985. Secretaria de Estado da Saúde. Portaria no 12 , de 24 de janeiro de 1985. Diário Oficial do Estado, 25 de janeiro de 1985, p. 10.

Sontag S 1984. A doença como metáfora. Ed. Graal, Rio de Janeiro. 108pp.

WHO, 1997. Anti-tuberculosis drug resistance in the world. The WHO/IUATLD Global Project on Antituberculosis Drug Resistance Surveillance, 19941997. World Health Organization Global Tuberculosis Programme, Geneva. 229pp. 